\title{
Life cycle assessment approach for refuse derived fuel (RDF) systems for Tuscany
}

\author{
A. Corti, L. Lombardi \\ Dipartimento di Energetica "Sergio Stecco" - Università degli Studi di \\ Firenze, Italy
}

\begin{abstract}
The recent MSW (Municipal Solid Waste) Italian Regulation highlights strategies that allow reduction of both landfill use for non stabilised organic waste and organic fraction waste to energy process feeding. For this purpose, the new regulation defines a refuse derived fuel (RDF) fraction, obtained by separation of finest and organic fractions, from commingled waste collection. RDF production systems, for every single waste collection and management defined area, need a following incineration system as tail end treatment for energy recovery, able to treat the obtained high Low Heat Value (LHV). Two main different strategies are applicable: one or more RDF incineration units for every single waste collection and management area or a minor waste to energy unit number with respect to waste collection and management area number.

An overall environmental load corresponds to each different scenario, due to all the different system components; the main aim of the work is to highlight the different scenario environmental balances, in order to indicate a possible solution having a minimum environmental load. Referring to the Tuscany Region territorial scale, an overall environmental balance was carried out based on a LCA (Life Cycle Assessment) approach, as a suitable instrument for direct and indirect impacts, resource depletion and saving evaluation, concerning different scenarios.
\end{abstract}

\section{Introduction}

The recent MSW Italian Regulation indicates some waste management priorities, in compliance with European Community guidelines: separate collection and recycle increment, reduction of non stabilised organic waste landfilling, waste to energy use for high LHV fractions. 
Refuse Derived Fuel (RDF, named in Italian as CDR) is defined as a tail end product, deriving from the separation of fine and organic fractions, coming from commingled waste collection.

Referring to the Tuscany Region, an overall production of commingled waste, for the year 2003, of about 1,606,000 tons has been estimated. This amount corresponds, based on the specific mechanical separation plant technical characteristics, to about 948,400 tons per year of combustible as produced fraction (fluff) [1]. Considering the existing incineration unit design heat rate value up to now, an overall amount of 717,900 tons per year has to be fed to new waste to energy units, which can be designed with a different heat rate (size) and different location.

Also, different fluff conditions can be considered: fluff as produced (humid), dry fluff and dry fluff in pellet.

The aim of this work is to compare all the different hypotheses by mean of Life Cycle Assessment (LCA) approach in order to have an overall environmental effects evaluation as a comparison base and to optimise the design criteria.

According to the definition of the Society of Environmental Toxicology and Chemistry [2]: "Life Cycle Assessment is a process to evaluate the environmental burdens associated with a product, process, or activity by identifying and quantifying energy and materials used and wastes released to the environment; to assess the impact of those energy and materials uses and releases to the environment; and to identify and evaluate opportunities to affect environmental improvements. The assessment includes the entire life-cycle of the product, process, or activity, encompassing extracting and processing raw materials; manufacturing; transportation and distribution; use, re-use, maintenance; recycling and final disposal".

Hence, LCA considers the possible impact on the different environmental components, also considering the non direct effect, deriving from the production processes of the manufactured materials entering the system boundary.

LCA approach can be an important strategy/decision making tool in waste management planning, when environmental evaluation of any used or possible technologies to collect, select, recycle, treat and dispose the wastes is carried out [3]. LCA studies are composed of several interrelated components: goal definition and scoping, inventory analysis, impact assessment, and improvement assessment.

\section{Goal definition and scoping}

The first component of an LCA study is the Goal Definition and Scoping. This component consists of defining the study purpose and its scope, establishing the functional unit.

As already stated, the aim of this study is the comparison of different possibilities of RDF treatment and RDF incineration plants localisation, with reference to the RDF production exceeding the existing plants designed capacity in the Tuscany Region. 


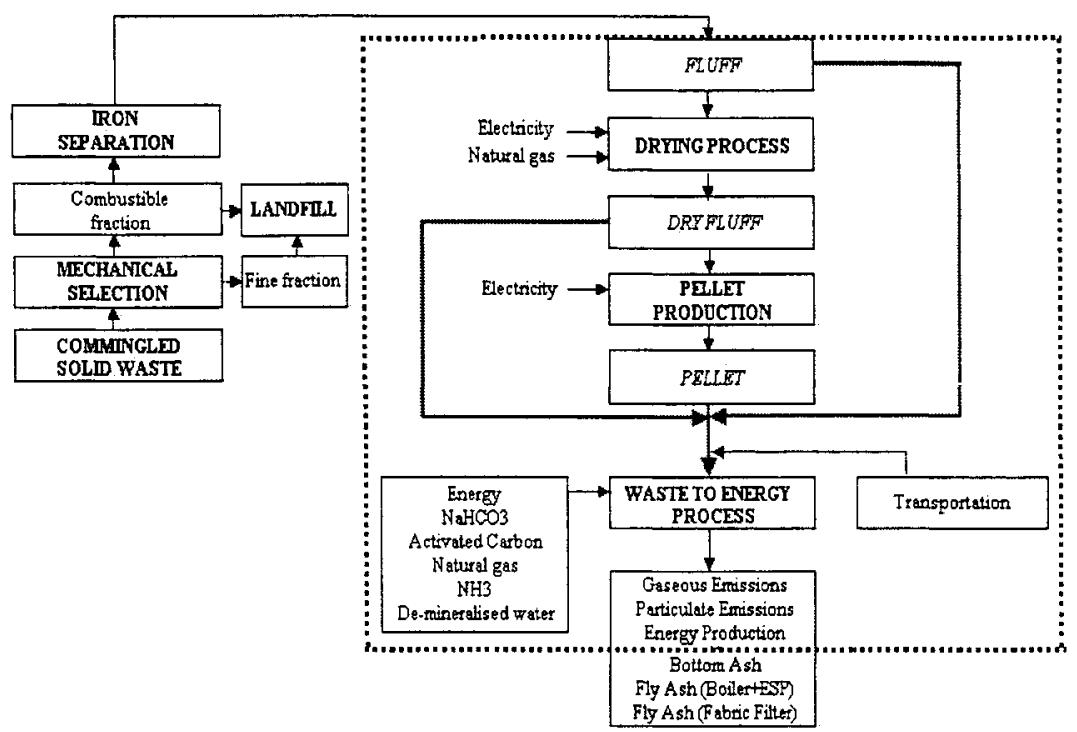

Figure 1: Studied system scheme.

The functional unit of the system is the mass unit $(1 \mathrm{~kg})$ of commingled solid waste, downstream the separated collection phase, from which the RDF is obtained, with reference to the exceeding treatment capacity of existing plants.

The studied system is represented in figure 1, where the previous phase of RDF selection is also schematised, even if this is not included within the boundary of the studied system. After several selection treatments, the first stage of RDF, called fluff, enters the system boundary. Here, it can undergo a drying process (dry fluff production) and then pellet production. Referring to the regional estimated fluff mass flow rate (717,900 ton per year) exceeding with respect to existing plants, an overall amount of 590,316 tons of dry fluff and 577,312 ton of pellet was estimated. The RDF at one of these refining stages can be fed to waste to energy process.

Inside the system boundary, the production processes of manufactured streams entering the system are included: electricity and natural gas for the drying process; electricity for the pellet production process; electricity, sodium carbonate, activated carbon, natural gas, ammonia and de-mineralised water for incineration process; RDF transport. The gaseous emissions, the particulate emissions and the energy production from the incineration system are considered, as well, while ashes further treatment is not accounted for, hence, ashes have been considered as simple solid wastes. 
Concerning the location of the incineration plants, three possibilities have been considered:

- one single plant for the entire region

- three plants dislocated within the region

- one single plant in each of the nine single waste collection and management areas.

While in this last case, the influence of transportation has not been considered because it is negligible when compared with the other cases - for the one single plant and the three regional plants, locations have been assumed, on the basis of barycentric considerations with respect to collection area and exceeding RDF mass flow rate. No studies on the real possibilities of building the plants in such locations have been carried out. The plants locations in the two cases are reported in figure 2 .

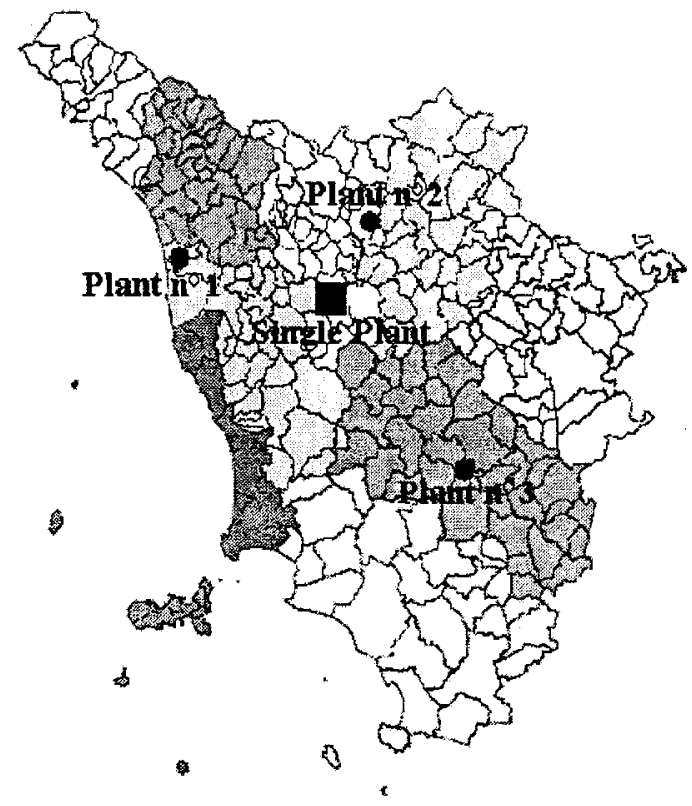

Figure 2: Hypothetical plant locations in the Tuscany Region, both in the case of three units and single unit.

Hence, the management hypotheses that have been compared in this study are as follows:

- Scenario A: fluff production and waste to energy process within each single waste collection and management area;

- Scenario B: fluff production and waste to energy process in three plants located within the region;

- Scenario C: fluff production and treatment in a single waste to energy plant located within the region; 
- Scenario D: dry fluff production and waste to energy process within each single waste collection and management area;

- Scenario $E$ : dry fluff production and waste to energy process in three plants located within the region;

- Scenario $F$ : dry fluff production and incineration in one single plant located within the region;

- Scenario $G$ : pellet production and treatment in a single waste to energy plant located within the region;

- Scenario $\boldsymbol{H}$ : pellet production and waste to energy process in three plants located within the region;

- Scenario I: pellet production and treatment in a single waste to energy plant located within the region;

\section{Inventory analysis}

Any product or service needs to be represented as a system in the inventory analysis methodology. A system is defined as a collection of materially and energetically connected operations (e.g. manufacturing process, transport process, fuel extraction process) which performs some defined function. The inventory analysis is a quantitative description of all flows of materials and energy across the system boundary either into or out of the system itself.

The input stream of $\mathrm{RDF}$, coming from the mechanical selection and iron separation, has the characteristics reported in table 1, which summarises the data for each of the nine waste collection and management areas.

The inputs and the outputs from the RDF refining process have been calculated by means of mathematical models - built in MATLAB - with reference to design working conditions of devices installed in an existing selection plant in Tuscany. The electric and thermal energy consumption for fluff drying and pellet production processes, as downstream material characteristics, has been calculated for the all nine different collection and management areas.

The inputs and the outputs from the RDF incineration process have been calculated by means of mathematical models - built in MATLAB ambient too. The considered model plant scheme includes the combustion unit, the heat recovery steam generator (HSRG), the electrostatic precipitator (ESP), the sodium bicarbonate absorbing unit for acid gas removal, the fabric filter (FF) and the nitrogen-oxides selective catalytic reduction (SCR).

Giving as input the RDF composition and characteristics, the model calculates automatically reactants and energy consumption (sodium bicarbonate, activated carbon, ammonia, de-mineralised water, electricity, natural gas), the process emissions (gaseous, solid, particulate) and the energy production.

The raw materials consumption and the emissions, due to the production processes of the manufactured materials used in the processes described above, have been retrieved from an Italian database devoted to LCA [4], compiled by the ANPA - the Italian national agency for the environment.

The inventory for the emissions and the fuel consumption for the transportation has been compiled with reference to CORINAIR database [5]. 
Transactions on Biomedicine and Health vol 5, (C) 2001 WIT Press, www.witpress.com, ISSN 1743-3525

Table 1 - Input RDF characteristics for each of the nine waste collection and management areas.

\begin{tabular}{|c|c|c|c|c|c|c|c|c|c|}
\hline Area & $\mathbf{1}$ & $\mathbf{2}$ & $\mathbf{3}$ & $\mathbf{4}$ & $\mathbf{5}$ & $\mathbf{6}$ & $\mathbf{7}$ & $\mathbf{8}$ & $\mathbf{9}$ \\
\hline $\begin{array}{c}\text { Surplus fluff } \\
\text { (t/a) }\end{array}$ & 44.906 & 90.246 & 23.459 & 44.839 & 244.328 & 118.346 & 69.843 & 30.889 & 51.036 \\
\hline $\begin{array}{c}\text { Commingled } \\
\text { waste (t/a) }\end{array}$ & 86.440 & 125.023 & 52.016 & 101.995 & 321.616 & 193.409 & 116.587 & 67.870 & 101.213 \\
\hline $\begin{array}{c}\text { fluff LHV } \\
\text { (kJ/kg) }\end{array}$ & 12.077 & 13.082 & 13.675 & 12.158 & 15.839 & 14.315 & 14.948 & 15.127 & 15.369 \\
\hline $\begin{array}{c}\text { Humidity } \\
\text { (\%) }\end{array}$ & 31.066 & 27.233 & 27.973 & 33.092 & 21.547 & 25.981 & 24.628 & 22.370 & 23.947 \\
\hline $\mathbf{C ~ ( \% )}$ & 28.734 & 30.323 & 31.447 & 27.954 & 35.137 & 32.306 & 33.375 & 34.661 & 34.274 \\
\hline $\mathbf{H ~ ( \% )}$ & 3.784 & 4.066 & 4.220 & 3.677 & 4.831 & 4.370 & 4.542 & 4.739 & 4.677 \\
\hline O (\%) & 22.505 & 22.464 & 23.928 & 20.356 & 23.013 & 22.790 & 22.781 & 25.852 & 23.517 \\
\hline $\mathbf{N ~ ( \% ) ~}$ & 0.756 & 0.610 & 0.612 & 0.691 & 0.572 & 0.605 & 0.593 & 0.553 & 0.587 \\
\hline $\mathbf{C l} \mathbf{( \% )}$ & 0.615 & 0.796 & 0.782 & 0.787 & 1.086 & 0.920 & 0.996 & 0.848 & 1.005 \\
\hline S (\%) & 0.126 & 0.121 & 0.128 & 0.115 & 0.120 & 0.122 & 0.121 & 0.133 & 0.124 \\
\hline Inert (\%) & 12.411 & 14.382 & 10.907 & 13.322 & 13.693 & 12.903 & 12.962 & 10.842 & 11.866 \\
\hline As (\%) & 0.00019 & 0.00019 & 0.00019 & 0.00019 & 0.00019 & 0.00019 & 0.00019 & 0.00019 & 0.00019 \\
\hline Cd (\%) & 0.00025 & 0.00025 & 0.00025 & 0.00025 & 0.00025 & 0.00025 & 0.00025 & 0.00025 & 0.00025 \\
\hline Pb (\%) & 0.01250 & 0.01250 & 0.01250 & 0.01250 & 0.01250 & 0.01250 & 0.01250 & 0.01250 & 0.01250 \\
\hline Hg (\%) & 0.00010 & 0.00010 & 0.00010 & 0.00010 & 0.00010 & 0.00010 & 0.00010 & 0.00010 & 0.00010 \\
\hline Zn (\%) & 0.01460 & 0.01460 & 0.01460 & 0.01460 & 0.01460 & 0.01460 & 0.01460 & 0.01460 & 0.01460 \\
\hline
\end{tabular}

\section{Impact assessment}

Life cycle impact assessment examines the mass and energy inventory input and output data for a product system to translate these data to better identify their possible environmental relevance and significance. This translation uses, where possible, numerical indicators for specific subjects or categories, where the indicator reflects in some manner the system environmental loading or resources depletion for that category. These indicators then constitute an environmental loading and resources depletion profile for a system. This profile with possible further analysis and weighting is intended to provide an additional useful perspective on the possible environmental significance in one or more general areas of resources, natural environment and human health.

In this study, environmental indicators according to the Eco-indicator'95 method have been used [6]. The impact categories and the environmental effects considered by this method are listed in table 2 , to which water consumption has been added.

The environmental effect indicators have been calculated for each scenario, according to the assumptions stated above, and results are reported in table 3. Values for the indicator of Solid Waste production (nr. 12) are negative because the obtained amount of fluff, downstream the commingled waste selection process, is considered as a reduction of landfilling demand, otherwise necessary.

A valuable goal of this kind of waste treatment is the reduction of landfill use. 
Table 2 - Eco-Indicator '95 environmental effects and units.

\begin{tabular}{|c|c|c|c|}
\hline \multirow{2}{*}{ Category } & \multicolumn{2}{|c|}{ Environmental Effect } & Units \\
\hline \multirow{3}{*}{$\begin{array}{c}\text { Environment } \\
\text { Protection }\end{array}$} & Greenhouse Effect & 1 & $\mathrm{~kg} \mathrm{CO}_{2}$ \\
\cline { 2 - 4 } & Ozone Layer Depletion & 2 & $\mathrm{~kg} \mathrm{CFC11}^{-}$ \\
\cline { 2 - 4 } & Acidification & 3 & $\mathrm{~kg} \mathrm{SO}_{2}$ \\
\cline { 2 - 4 } & Eutrophication & 4 & $\mathrm{~kg} \mathrm{PO}_{2}$ \\
\hline \multirow{4}{*}{ Human Health } & Heavy Metals & 5 & $\mathrm{~kg} \mathrm{~Pb}$ \\
\cline { 2 - 4 } & Carcinogens & 6 & $\mathrm{~kg} \mathrm{Benzo[a]pyrene}$ \\
\cline { 2 - 4 } & Winter Smog & 7 & $\mathrm{~kg} \mathrm{SPM}$ \\
\cline { 2 - 4 } & Summer Smog & 8 & $\mathrm{~kg} \mathrm{C} \mathrm{H}_{4}$ \\
\cline { 2 - 4 } & Pesticides & 9 & $\mathrm{~kg} \mathrm{active} \mathrm{substances}$ \\
\hline \multirow{3}{*}{$\begin{array}{c}\text { Resources } \\
\text { Depletion }\end{array}$} & Water Consumption & 10 & $\mathrm{Kg}$ \\
\cline { 2 - 4 } & Energy & 11 & $\mathrm{MJ}$ \\
\cline { 2 - 4 } & Solid Waste & 12 & $\mathrm{Kg}$ \\
\hline
\end{tabular}

Table 3 - Environmental effect indicators values for the assumed scenarios (environmental indicators are numbered as in table 2 and measured in the respective units per $\mathrm{kg}$ of inlet $\mathrm{SW}$ ).

\begin{tabular}{|c|c|c|c|c|c|c|c|c|c|}
\hline $\begin{array}{c}\text { Scenario } \\
\text { Effect }\end{array}$ & A & B & C & D & $\mathbf{E}$ & F & G & H & I \\
\hline 1 & 0.8187 & 0.8211 & 0.8435 & 0.8090 & 0.8108 & 0.8294 & 0.8190 & 0.8207 & 0.8389 \\
\hline 2 & $\mathrm{E}-11$ & $7 \mathrm{E}-11$ & $3.7 \mathrm{E}-11$ & $5 E-11$ & $3.5 \mathrm{E}-11$ & $3.5 \mathrm{E}-11$ & $3.6 \mathrm{E}-11$ & $3.6 \mathrm{E}-11$ & $3.6 \mathrm{E}-11$ \\
\hline 3 & 0.00080 & 0.00082 & 0.00101 & 0.00081 & 0.00082 & 0.00098 & 0.00086 & 0.00087 & 0.00103 \\
\hline 4 & $9.3 \mathrm{E}-05$ & $9.7 \mathrm{E}-05$ & 0.00013 & $9.2 \mathrm{E}-05$ & $9.6 \mathrm{E}-05$ & 0.00012 & $9.5 \mathrm{E}-05$ & $9.8 \mathrm{E}-05$ & 0.00012 \\
\hline 5 & $8.3 \mathrm{E}-07$ & $8.9 \mathrm{E}-07$ & $1.3 \mathrm{E}-06$ & $7.2 \mathrm{E}-07$ & $7.6 \mathrm{E}-07$ & $1.1 \mathrm{E}-06$ & $7.5 \mathrm{E}-07$ & $8 \mathrm{E}-07$ & $1.1 \mathrm{E}-06$ \\
\hline 6 & $3.9 \mathrm{E}-08$ & $3.9 \mathrm{E}-08$ & $4.1 \mathrm{E}-08$ & $3.8 E-08$ & $3.8 \mathrm{E}-08$ & $3.9 \mathrm{E}-08$ & $3.8 \mathrm{E}-08$ & $3.8 \mathrm{E}-08$ & $4 \mathrm{E}-08$ \\
\hline 7 & 0.00035 & 0.00035 & 0.00041 & 0.00036 & 0.00036 & 0.00041 & 0.00040 & 0.00040 & 0.00045 \\
\hline 8 & .00181 & 0.00181 & 0.00186 & 0.00174 & 0.00174 & 0.00178 & 0.00177 & 0.00178 & 0.00182 \\
\hline 9 & 0 & 0 & 0 & 0 & 0 & 0 & 0 & 0 & 0 \\
\hline 10 & 2.70764 & 2.67644 & 2.70502 & 2.75056 & 2.71794 & 2.74428 & 3.07849 & 3.04549 & 2.21948 \\
\hline 11 & 8.614 & 8.611 & 8.603 & 8.285 & 8.284 & 8.282 & 8.424 & 8.423 & 8.421 \\
\hline 12 & -0.48939 & -0.48938 & -0.48928 & -0.38270 & -0.38269 & -0.38258 & -0.37055 & -0.37054 & -0.37043 \\
\hline
\end{tabular}

Each environmental indicator can be compared for the different scenarios. In figure 3 the detailed comparisons for the Greenhouse Effect is reported, as result example. Concerning this specific effect, for example, the scenarios $\mathrm{C}, \mathrm{F}$ and I have a higher value, because of the influence of transportation to the single incineration plant. In general, most indicators increase as the distance of transport increases. None of the studied scenarios corresponds to a minimisation 


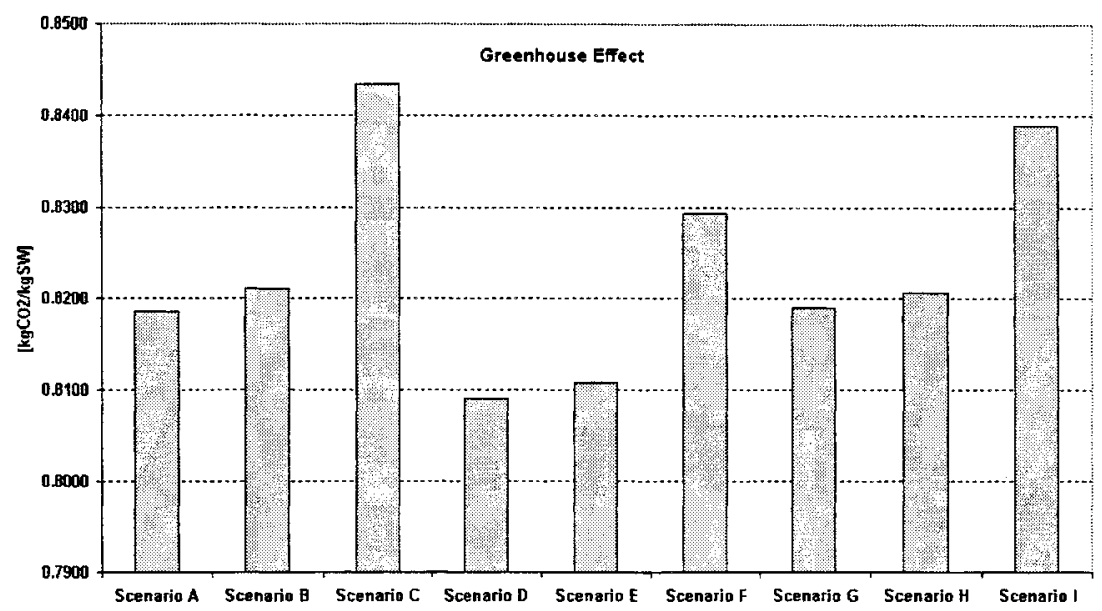

Figure 3: Greenhouse Effect indicator comparison for the nine scenarios.

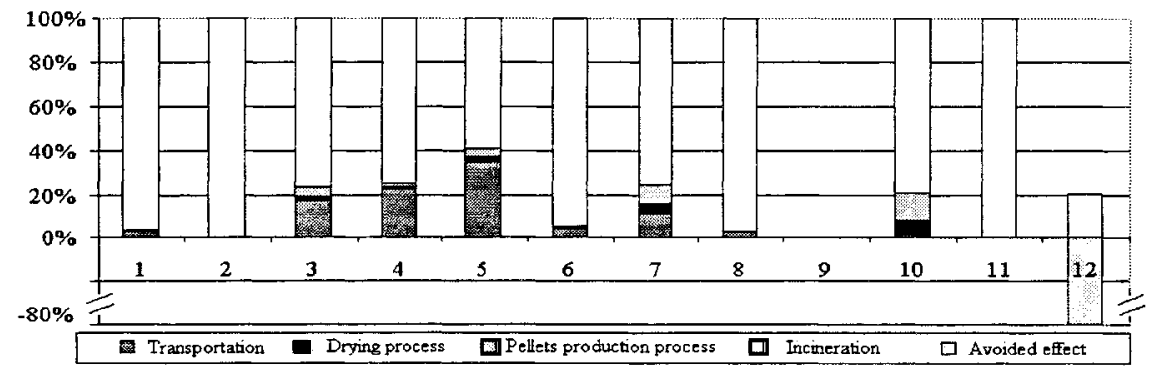

Figure 4: Involved processes contribution to the total values of each environmental indicator (numbers correspond to table 3).

of all the environmental indicators (the bold cells in the table correspond to the minimum for each indicator), even if the scenario D - dry fluff production and waste to energy treatment plants located within each single waste collection and management area - gives as a result the highest number of lowest values. Moreover the $\mathrm{D}$ scenario can be highlighted, depending on the different environmental indicators, as the minimal effect load condition or however as a condition of relative low load.

Another interesting result is shown in figure 4 . Here, the contribution of the different processes involved to the total of each indicator is reported for the scenario I.

It is clear that the highest contribution to the total value of all the indicators is due to the incineration process. Also transportation has a considerable importance, but only relating to some indicators such as Acidification, 
Eutrophication and Heavy Metals. The avoided effects are present, obviously, only for the Solid Waste production indicator, representing the net landfill use saving.

Since there is not a scenario that minimises all the environmental effects, it is possible to use a final single indicator that summarises all the indicators. This value is calculated giving to each indicator a weighting factor, that allows reporting the indicator values on the same reference scale and, hence, adding them together in terms of eco-points [6]. The weighting factors are calculated on the basis of the Distance-to-Target principle, which means that an effect's seriousness is evaluated in terms of the distance between its current and a target level. In this case the Eco-indicator'95 method has been used [6], basing target values on a certain measurable damage.

A high damage level results in a higher target value. In general, the problem is establishing the target value on the basis of scientific knowledge, in order to make the evaluation as objective as possible. Even if this phase of the LCA has still to be developed, in this sense, it is quite useful to have a final indicator value that can give a synthetic indication on the scenario with the lowest impact.

Figure 5 reports the final indicator values for the studied scenarios with the contribution of the different process within the analysed system.

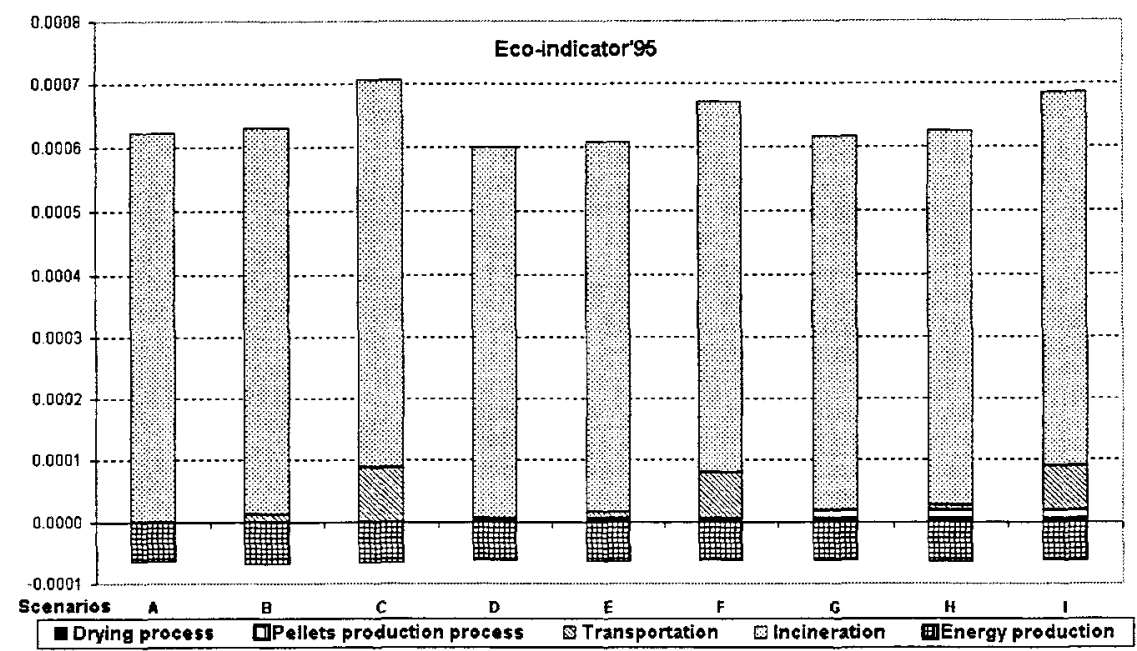

Figure 5: Eco-indicator' 95 values for the final comparison of the analysed scenarios

The energy production contribution negative values represent the avoided effect obtained producing electricity by means of energy recovery from incineration in the place of conventional energy conversion national system.

From the analysis of the final indicator it is possible to state that the scenario with the lowest impact is the scenario D - dry fluff production and waste to energy process within each single waste collection and management area. This 
means that the pellet production process, being a high energy consuming process, gives a high negative contribution.

Concerning transportation, even if the higher size of the single incineration plant for the entire region assures better performances and lower emission values, this is not enough to justify the transportation from each single waste collection and management area to the centralised plant, even if the difference between the three transportation possibilities is not high. Finally, the scenario with the highest indicator value is $\mathrm{C}$, corresponding to fluff production and treatment in a single waste to energy plant located within the region.

\section{Conclusions}

Different possibilities of processing RDF, obtained from MSW selection, have been studied. Nine scenarios, with different plant locations and different intermediate stage RDF production, have been compared by means of Life Cycle Assessment. The scenario with the lowest value for the final eco-indicator turns out to be the one with dry fluff production and waste to energy process within each single waste collection and management area.

With reference to this study-case a methodology, based on LCA, for supporting decision makers in the field of integrated waste management has been developed. This methodology application can be highlighted as suitable, because it allows one to consider - at the same time - the impact on different environmental factors concerning all the processes that have to be considered for a complex system referring to production, collection, transport, treatment and disposal of waste.

Of course, this kind of analysis, being an environmental balance procedure, refers to global environmental effects, and has to be linked to the specific territorial impact evaluation instruments (Environmental Impact Assessment), for an environmental compliance study.

\section{References}

[1] Pacini, P., "Metodologie LCA per la valutazione di scenari di smaltimento di RDF per la Regione Toscana", Tesi di Laurea in Ingegneria per l'Ambiente ed il Territorio - Università degli Studi di Firenze - 2001 - in Italian

[2] Consoli, F., et al., Guidelines for Life-Cycle Assessment: $A$ "Code of Practice", 1993, SETAC

[3] Corti, A., Sirini, P., Carnevale, E. "LCA model applied to municipal solid waste management and treatment scenarios" International Symposium on Sanitary and Environmental Engineering, Trento, 18-21 September 20Q0

[4] I-LCA - "Banca dati italiana a supporto della valutazione del ciclo di vita", ANPA, versione 2 ottobre 2000 - in Italian

[5] EMEP- CORINAIR - Emission Inventory Guidebook, European Environment Agency 1999

[6] Mark Goedkoop, "The Eco-indicator'95 - Final Report", PRé Consultants, Amersfoort - The Netherlands 